\title{
Fluorescence in situ hybridization (FISH): an increasingly demanded tool for biomarker research and personalized medicine
}

\author{
Linping $\mathrm{Hu}^{1,6+}$, Kun $\mathrm{Ru}^{1,2+}$, Li Zhang ${ }^{1,3}$, Yuting Huang ${ }^{4}$, Xiaofan Zhu ${ }^{1,3,6}$, Hanzhi Liu ${ }^{1,6}$, Anders Zetterberg ${ }^{5}$,
} Tao Cheng ${ }^{1,6^{*}}$ and Weimin Miao ${ }^{1,6^{*}}$

\begin{abstract}
Extensive studies of the genetic aberrations related to human diseases conducted over the last two decades have identified recurrent genomic abnormalities as potential driving factors underlying a variety of cancers. Over the time, a series of cutting-edge high-throughput genetic tests, such as microarrays and next-generation sequencing, have been developed and incorporated into routine clinical practice. Although it is a classical low-throughput cytogenetic test, fluorescence in situ hybridization (FISH) does not show signs of fading; on the contrary, it plays an increasingly important role in detecting specific biomarkers in solid and hematologic neoplasms and has therefore become an indispensable part of the rapidly developing field of personalized medicine. In this article, we have summarized the recent advances in FISH application for both de novo discovery and routine detection of chromosomal rearrangements, amplifications, and deletions that are associated with the pathogenesis of various hematopoietic and non-hematopoietic malignancies. In addition, we have reviewed the recent developments in FISH methodology as well.
\end{abstract}

Keywords: Fluorescence in situ hybridization (FISH), Solid tumors, Hematopoietic malignancies, Genetic aberrations, Biomarkers, Personalized medicine

\section{Introduction}

Mounting evidence indicates that both hematologic and solid tumors are heterogeneous disorders with diverse genomic aberrations [1-3]. Due to the extensive investigations of the correlation between genomic instability and disease pathogenesis conducted over the last two decades, an increasing number of genomic abnormalities such as gain, loss or rearrangement of chromosomal fragments and gene mutations, have been found to be driving factors in the pathogenesis of various malignancies. Over the time, a series of cutting-edge cytogenetic and molecular tests have been developed for detecting such genomic aberrations, which allows more accurate

\footnotetext{
* Correspondence: chengt@pumc.edu.cn; miaowm@hotmail.com ${ }^{\dagger}$ Equal contributors

${ }^{1}$ State Key Laboratory of Experimental Hematology, Institute of Hematology and Blood Diseases Hospital, Chinese Academy of Medical Sciences and Peking Union Medical College, Tianjin, China

${ }^{6}$ Center for Stem Cell Medicine, Chinese Academy of Medical Sciences and Peking Union Medical College, Nanjing Road 288, Tianjin 300020, P.R. China Full list of author information is available at the end of the article
}

molecular profiling for individual patients. The advanced molecular pathology techniques [4] enable better disease stratification and prognosis, leading to tailored therapeutic regimens. Apparently, a new era of personalized medicine has arrived much earlier than most of us expected [3].

Fluorescence in situ hybridization (FISH) is a cytogenetic technique developed in the early 1980s. FISH uses fluorescent DNA probes to target specific chromosomal locations within the nucleus, resulting in colored signals that can be detected using a fluorescent microscope. Compared to the conventional cytogenetic (CC) metaphase karyotype analysis, FISH does not require cell culturing, and can directly use fresh or paraffin-embedded interphase nuclei for a rapid evaluation. With the discovery of numerous disease-related genes in recent years, the applications of FISH broadened to include more genetic diseases, hematologic malignancies, and solid tumors. For example, FISH detection of BCR/ABL1 translocation, HER2 amplification, and ALK rearrangement is critical for guiding targeted therapy in chronic 
myeloid leukemia [5], breast cancer [6,7] and lung adenocarcinoma, respectively [8,9]. Hence, FISH tests have been recognized as vital components of personalized medicine.

With respect to biomarker detection, a series of innovative high-throughput molecular tests, such as array-based comparative genome hybridization $(\mathrm{aCGH})$, single nucleotide polymorphism (SNP) arrays, and next generation sequencing, have recently been developed and incorporated into routine clinical practice. The stunning technology replacing speed raised a serious question: is a classical low-throughput assay, such as FISH, poised for replacement? However, the answer is quite the opposite. In fact, FISH has become increasingly important in clinical diagnosis due to its simplicity and reliability in evaluating key biomarkers in various tumors [5]. In this article, we aim to review the advances in FISH for disease biomarker detection and personalized medicine applications.

\section{Hematopoietic malignancies Leukemia}

Leukemia is a heterogeneous clonal disorder of hematopoietic stem and progenitor cells, characterized by various acquired genetic aberrations. The discovery of abnormal fusion proteins resulting from chromosomal rearrangements has significantly contributed to our understanding of the molecular mechanism of the pathogenesis of leukemia. The first oncogene discovered as the direct etiological basis of a malignancy, the BCR/ABL1 translocation in chronic myeloid leukemia (CML), results in dysregulated tyrosinase activity, which can be treated using the tyrosine kinase inhibitor Imatinib [10,11]. The $\mathrm{t}(15 ; 17)$ chromosomal translocation in promyelocytic leukemia (APML, AML-M3) functions in a similar way, generating the novel fusion protein PML/RARa, and ATRA (all-trans retinoic acid) offers an effective therapy for APML by specifically suppressing oncogenic activities of the PML/RARa fusion protein [12,13]. The FISH assay is considered the gold standard for detecting these chromosomal translocations and it therefore plays a crucial role in selecting a targeted therapy for various leukemias.

Over the last two decades, additional recurrent genetic aberrations have been identified in leukemias, improving molecular sub-classification and allowing stratified management. Whereas most of the chromosomal rearrangements can be detected using $\mathrm{CC}, \mathrm{FISH}$ remains the most robust tool for detecting balanced or unbalanced chromosomal aberrations. Furthermore, a combination of cytogenetic and molecular profiling permits more accurate assessment of the disease prognosis [1].
In addition to the common chromosomal rearrangements in acute myeloid leukemia (AML), which are $\mathrm{t}(8 ; 21)(\mathrm{q} 22 ; \mathrm{q} 22), \mathrm{t}(15 ; 17)(\mathrm{q} 22 ; \mathrm{q} 12)$ and $\operatorname{inv}(16)(\mathrm{p} 13.1 \mathrm{q} 22)$ or $\mathrm{t}(16 ; 16)(\mathrm{p} 13.1 \mathrm{q} 22)$ [14], newly obtained molecular information has been combined with cytogenetic findings to establish a more comprehensive risk assessment system. Among them, $\mathrm{t}(8 ; 21)(\mathrm{q} 22 ; \mathrm{q} 22) / \mathrm{RUNX} 1-\mathrm{RUNX} 1 \mathrm{~T} 1$; $\mathrm{t}(15 ; 17)$ (q22;q12)/PML-RARa; inv (16)(p13.1q22) or $\mathrm{t}(16 ; 16)(\mathrm{p} 13.1 ; \mathrm{q} 22) / \mathrm{CBFB}-\mathrm{MYH} 1$ and mutation in both the CEBPA and NPM1 genes are associated with a good clinical outcome, whereas $\mathrm{t}(1 ; 22)$ (p13;q13)/RBM15MKL1; inv(3)(q21q26.2) or t(3;3)(q21;q26.2)RPN1-EVI1; $\mathrm{t}(6 ; 9)(\mathrm{p} 23 ; \mathrm{q} 34) / D E K-N U P 214$, the MLL gene rearrangement, complex karyotypes, and mutations in both KIT and FLT3 are associated with a less favorable prognosis $[14,15]$.

Acute lymphoblastic leukemia (ALL) occurs mostly in children between the ages of 1 to 5 years old. The most common chromosomal translocations in ALL are t $(9 ; 22)$ (p190) in adults, and $t(12 ; 21)$ in children respectively. The most frequent numerical aberration in ALL is hyperdiploidy with chromosome numbers ranging from 51 to 63, with chromosomes X, 4, 6, 10, 14, 17 and 18 generally being trisomic and chromosome 21 frequently occurring as four copies [16,17]. Among them, patients with $\mathrm{t}(12 ; 21)$, $\mathrm{t}(1 ; 19)$, and hyperdiploidy have a favorable outcome, whereas patients with MLL translocations have a worse prognosis. It is worth noting that the presence of $t(9 ; 22)$ used to indicate the worst prognosis for ALL patients, but this fact has dramatically changed since the introduction of the "magic bullet" Gleevec.

Due to the universal presence of BCR/ABL1 rearrangement in chronic myeloid leukemia (CML), it is now defined as the diagnostic hallmark of CML $[10,11,18]$.

Chronic lymphocytic leukemia (CLL) generally presents as an indolent disorder but can be aggressive in some patients due to various genetic aberrations. The most common recurrent chromosomal abnormalities are trisomy 12, del(13q), del(11q), del(17p) and del(6q) [19-21]. FISH can identify chromosomal rearrangements in approximately $80 \%$ of patients, whereas CC can identify chromosomal aberrations in only approximately 40-50\% patients. The genetic information provided by FISH tests can be critical for therapeutic decisions. Chemoimmunotherapy using fludarabine, cyclophosphamide and rituximab (FCR) receives a better treatment response from patients with trisomy 12 or $\operatorname{del}(11 \mathrm{q})$, whereas patients with $17 p$ deletions do not benefit from FCR treatment at all $[20,22]$. In addition to the therapeutic significance, FISH tests facilitate differential diagnosis between CLL and other types of small B-cell lymphoma/leukemia. For example, mantle cell lymphoma is morphologically similar to CLL, but carries a characteristic genetic aberrancy, the cyclin D1 translocation, and has a much worse prognosis. The FISH test is the gold standard method of identifying 
the cyclin D1 rearrangement, particularly in when immunohistochemistry is not contributory for various reasons.

\section{Multiple myeloma}

Multiple myeloma (MM) is another heterogeneous malignancy of terminally differentiated B cells, clinically manifested as monoclonal plasma cells that infiltrate the bone marrow, a spike of monoclonal immunoglobulin in the blood and/or urine, and massive osteolytic bone lesions. Similar to the other hematologic neoplasms, MM is characterized by a complex pattern of extensive genomic aberrations involving many chromosomes [23,24]. The genetic abnormalities found in MM can be roughly divided into two categories based on the chromosome ploidy status and other parameters [25,26]. The hyperdiploid karyotype is generally associated with trisomies of many chromosomes, such as $3,5,7,11,15,19$ and 21 , whereas the hypodiploid karyotype appears to be more frequently associated with a translocation of immunoglobulin heavy chain (IGH) locus at 14q32 [26]. The IgH (14q32) translocations found in hypodiploid MM can involve many different partners, such as 11q13 (CCND1), 6p21 (CCND3), 16q23 (MAF), 20q12 (MAFB), and 4p16 (FGFR3 and MMSET). Furthermore, the chromosome ploidy status and IGH rearrangements were found to be correlated with disease outcome in MM patients [25]. For example, the hyperdiploid karyotype with $\mathrm{t}(11 ; 14)(\mathrm{q} 13 ; \mathrm{q} 32)$ indicates a better prognosis, whereas the hypodiploid karyotypes with $\mathrm{t}(4 ; 14)(\mathrm{p} 16 ; \mathrm{q} 32)$ or $\mathrm{t}(14 ; 16)(\mathrm{q} 32 ; \mathrm{q} 23)$ imply a worse clinical outcome $[25,26]$.

Molecular studies have demonstrated that primary translocations occur in the early stage of MM, followed by large number of secondary translocations during tumor progression [27]. It is believed that the secondary genomic aberrations are responsible for a more proliferative phenotype in the advanced stage of MM. Certain genetic aberrations, such as MYC rearrangements, del (13q), del (17p), and the deletion of $1 p$ and/or amplification of 1q, have been identified as the most common secondary aberrations in MM [27-29]. The chromosome 13 deletion or chromosome 13 monosomy occurs in $50 \%$ of the patients with advanced MM and are associated with an aggressive clinical course and an unfavorable prognosis [30,31]. Deletion of 17P13, presumably resulting in $\mathrm{LOH}$ (loss of heterozygosity) of P53, has been determined to be associated with a very poor clinical outcome [32,33]. Chromosome 1p deletion or 1q amplification is the most common structural aberration found in $M M$ and is associated with an unfavorable prognosis [34-36].

Due to the low proliferative rate of tumor cells in the early stage of MM, CC analysis of metaphase cells is likely to miss detecting the primary genomic aberrations in non-dividing tumor cells. Furthermore, some small chromosomal rearrangements in MM may be cryptic to chromosome banding analysis. Thus FISH, which is effective for analysis of interphase nuclei and small chromosomal aberrations, is recognized as the most robust genetic test for characterizing the known cytogenetic abnormalities in MM. Nevertheless, integration of data from the multiple genetic profiling techniques including CC, FISH, RT-PCR, and gene mutation analysis, among others, would provide comprehensive information for better stratification of MM patients with diagnostic and prognostic significance.

\section{Myelodysplastic syndromes (MDS)}

MDS is a heterogeneous group of clonal hematopoietic disorders characterized by blood cytopenias resulting from ineffective hematopoiesis. The clinical outcome of MDS is variable, and approximately 20 to $30 \%$ of the patients will progress to AML within a few months or years [37]. Recurrent chromosomal abnormalities, such as $-5 / \operatorname{del}(5)(\mathrm{q} 31),-7 / \operatorname{del}(7)(\mathrm{q} 31),+8, \operatorname{del}(20)(\mathrm{q} 2),-17 / \mathrm{del}$ (17)(p3.1), and $-Y$, are found in half of the de novo MDS cases. The cytogenetic finding is closely related to the clinical outcome, and thus has been incorporated into the revised international prognostic scoring system (IPSS-R) and the WHO prognostic scoring system (WPSS) [38]. In addition, certain chromosomal aberrations, such as $-5 / 5 q^{-},-7 / 7 q_{-}$, and complex abnormalities, were found to be correlated to the response to chemotherapy $[37,39,40]$. The metaphase chromosomal banding assay is regarded as the objective standard for clonal analysis of MDS. Being a more sensitive test, FISH can be utilized to identify minor abnormal clones and cryptic chromosomal aberrations that are undetectable using $\mathrm{CC}$ and to provide additional information for patients with a normal karyotype or unsuccessful culture [5,39]. With the introduction of high-resolution assays such as aCGH and SNP arrays, it will be possible to discover additional genetic markers in the near future, leading to more accurate diagnoses, better targeted therapies, and more clinically significant judgment of the prognosis for MDS patients [41].

\section{Non-hematopoietic malignancies (solid tumors) Lung cancer}

Anaplastic lymphoma kinase (ALK) rearrangements, which are generally associated with pulmonary adenocarcinomas in female non-smokers, occur in approximately 5\% of patients with non-small cell lung cancer (NSCLC). ALK rearrangements mostly result from the fusion of the echinoderm microtubule-associated protein-like 4 (EML4) with ALK at chromosome 2p23. Fusion of ALK kinase with EML4 or other fusion partners, such as TFG or KIF5B, leads to constitutive activation of ALK kinase [39,42]. Patients with EML4-ALK fusion-positive NSCLC, 
who were treated with the small-molecule kinase inhibitor Crizotinib, showed a response rate of 50-60\% [8]. 2011 was the first time that the US FDA simultaneously approved a novel anti-cancer drug (Crizotinib, Pfizer) and its companion FISH detection kit (ALK FISH probe kit, Abbott Molecular), which highlighted the critical role of the FISH assay in guiding ALK-targeted therapy [8,9]. Because ALK rearrangements are reportedly mutually exclusive with EGFR/KRAS mutations [43], ALK FISH testing is generally recommended for patients with wild-type EGFR/KRAS non-squamous NSCLC.

Using the ALK FISH detection kit, the 3' and 5' ends of the ALK gene are differentially labeled with red or green fluorescent probes. In benign cells, two fused signals should be detected. In $60-70 \%$ of all of the ALK rearrangements, the EML4-ALK gene fusion occurs through only inversion, and therefore narrowly separated (two to three signals apart) red and green signals are detected in addition to the normal fusion signal. In the other $30-40 \%$ of the cases, gene fusion occurs through an interstitial deletion together with an inversion of EML4, which lead to a single red signal without a corresponding green signal, in addition to the normal fusion signal [44].

ROS1, another receptor tyrosine kinase, which is located at chromosome $6 \mathrm{p} 22$, has recently been found to be rearranged in $2-3 \%$ of the NSCLC adenocarcinomas [7,45]. In addition, several ROS1 translocation partners, e.g., TPM3, SDC4, SLC34A2, CD74, EZR or LRIG3, have been found forming a fusion with the kinase domain of ROS1, leading to constitutive activation of ROS1 and increase in malignant transformation activity [7]. The ROS1 rearrangements define a subset of NSCLC with clinical characteristics and treatment responses that are similar to those of the ALK rearrangements [45,46]. Therefore, this type of rearrangement is another predictive FISH biomarker that can be applied to personalized management of lung cancer.

\section{Prostate cancer}

Rearrangements involving androgen-regulated TMPRSS2 and ETS family members (ERG, RTV1, ETV4) were detected in nearly half of the prostate cancers but none of the benign prostate tissues that were tested [5,39]. The relevance of the TMPRSS2 rearrangements to the pathogenesis, prognosis, and targeted therapy of prostate cancer has made it a predictive biomarker for prostate cancer [47]. The most common type of chromosome rearrangement involves the fusion of TMPRSS2 to the oncogene ERG, which leads to the abnormal activation of ERG. Identification of these rearrangements may allow stratification of prostate cancers into subtypes that respond to specific therapies. As the test of choice for chromosomal rearrangements, FISH was successfully applied to frozen as well as formalin-fixed paraffin- embedded (FFPE) prostate cancer samples with high sensitivity and specificity. Initially, a kit containing dual-color ERG break-apart probes that can identify rearrangement of the ERG gene but do not indicate the 5 '-partner to which ERG is fused to, was used $[48,49]$. Later on, a tricolor FISH assay was developed by combining the red/green break-apart probes for TMPRSS2 with an orange-labeled fusion probe for the 3' region of ERG [50,51]. Recently, a four-color FISH assay was reported, which allows the detection of either TMPRSS2 or ERG rearrangements regardless of the partner gene [39].

\section{Breast cancer}

Breast cancer is a fairly heterogeneous malignancy that involves large numbers of genomic aberrations that are inherited or are acquired during the initiation and progression of the disease. To date, the most successful application of FISH as a companion diagnostic test for selecting a targeted therapy for a solid tumor may be the FISH evaluation of Her-2 amplification for breast cancer [52-54]. Her-2 (human epidermal growth factor receptor-2), also called c-erbB-2, is located at chromosome 17q12-21.32, and encodes a trans-membrane protein of $185 \mathrm{kDa}$. Her-2 protein is an active tyrosine kinase that plays an important role in normal cell growth and differentiation. It has been reported that Her-2 gene amplification occurs in $20-30 \%$ of breast cancer patients. Her-2 gene amplification leads to its overexpression on the cell surface. Her-2 amplification indicates a bad prognosis, short survival time, and the existence of a more aggressive phenotype of tumor cells. Her-2 overexpressed breast cancer may be resistant to endocrine therapy and some chemotherapies; however, it is sensitive to Herceptin treatment and exhibits more responsiveness to paclitaxel and anthracyclines [55]. At present, there are both IHC and FISH assays for measuring Her-2 overexpression. The former assay is simplistic, convenient, and cost-saving, but it can be affected by various factors and the staining result could be ambiguous. The latter is relatively sophisticated and expensive, but the staining result is more accurate. Therefore, the FISH assay is regarded as the gold standard for clinical evaluation of the Her-2 status and is generally recommended in when the IHC result could not clarify the Her-2 status.

Traditionally, breast cancer is classified as high risk and low risk based on the tumor's size, grade, nodal and ER status. However, it is noted that $15 \%$ of patients with low risk parameters (tumor size $<1 \mathrm{~cm}$, low grade, lymph node negative, ER positive) have recurrent disease and usually die of metastasis. Meanwhile, $15 \%$ of patients in the high risk group (tumor size $>5 \mathrm{~cm}$, high grade, lymph node positive, ER negative) have unexpected favorable clinical outcome. These patients could receive 


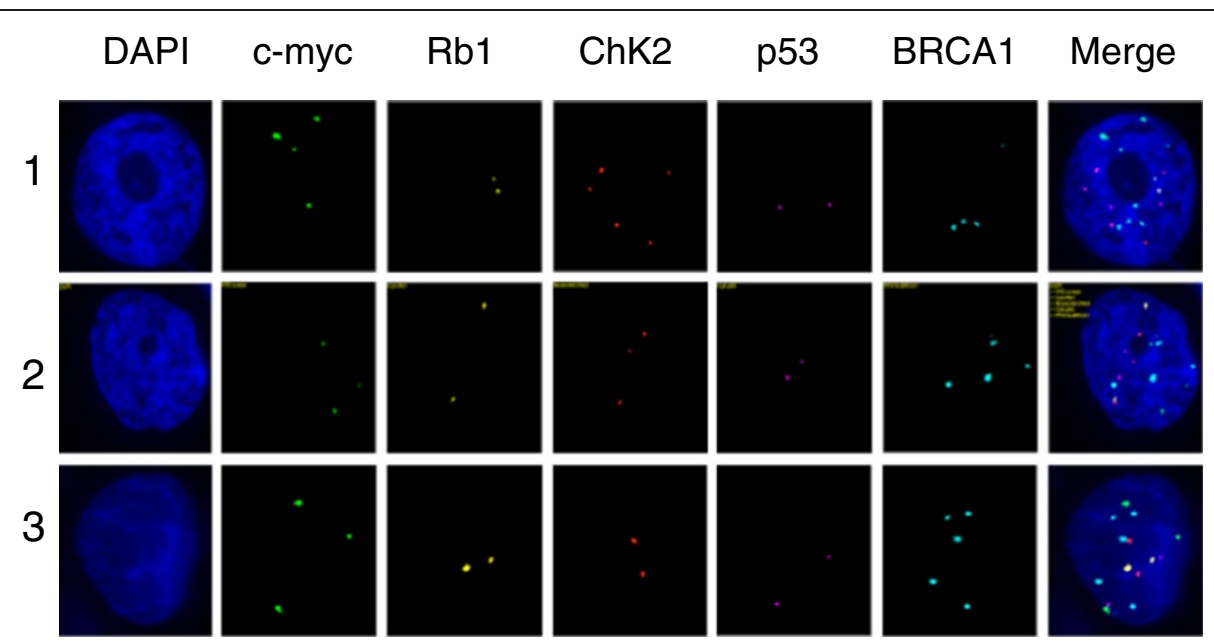

Figure 1 The three subclones from the ascites cytospin sample of a progressive epithelial ovarian cancer patient. BAC probes containing the c-myc, Rb1, Chk2, p53 or BRCA1 genes were labeled with Spectrum Green, PF555 (red), PF590 (orange), HyPer5 (purple) or PF415 (blue), respectively. The mixed probes were hybridized with the ascites cytospin sample from a progressive epithelial ovarian cancer patient. The results revealed that there were three subclones showing distinct combinations of signal patterns for the five selected genes. The details of the molecular profiling are shown in Table 1.

mistreatments based on their histopathological classifications; therefore, there is a need to establish more accurate molecular classification schemes [56]. A molecular classification based on a clustering analysis of the expression patterns of 427 genes has divided breast cancer into four types: a luminal type (further divided into $\mathrm{A}, \mathrm{B}$ and $\mathrm{C}$ subtypes), a basal-like type, a Her-2 positive type, and a normal breast-like type $[57,58]$, and the molecular classifications are closely correlated with the prognoses, with the luminal subtype A having a good clinical outcome; the luminal subtype B having a bad prognosis; and the basal-like and the Her-2 positive types having the worst clinical outcome [58]. Recent $\mathrm{CGH}$ analyses of genomic aberrations in breast cancer have identified three molecular categories of breast cancers. The first category, called "simplex" [59] or 1q/16q [60,61], is characterized by a few genomic rearrangements and the second category, called "complex sawtooth" [59] or "complex" [60,61], is characterized by more rearrangements and gene copy number alterations within a restricted genomic area. The third category, called "complex firestorm" [59] or "mixed amplifier" [60,61], is characterized by high intensity gene amplification profiles restricted to a small genomic areas. Interestingly, correlations seem to exist between the previous Sorlie expression classes [58] and the specific genomic profile categories, possibly due to the interplay of the genomic aberrations and the overall gene expression. The luminal A type of breast cancer is correlated with the simplex profile and the luminal B and the Her-2 positive types with the complex firestorm profile. The basal-like class is correlated with the complex sawtooth profile [62].
The estrogen receptor (ER) is a well-established biomarker for endocrine therapy in breast cancer patients, while the progesterone receptor (PR) is not. Clinical studies showed that ER + PR + breast cancer shows a better response to endocrine therapy, whereas ER + PRbreast carcinoma has a more aggressive phenotype and a poorer response to endocrine therapy. CGH and FISH studies have revealed that ER + PR- breast cancers have higher genomic instability profiles, including recurrent amplifications in 11q13, 12q14-q15, 17q21-q25, and 20q13 and deletions in 11q13-q15 [60,63-65]. A more recent study refined the area to $17 \mathrm{q} 23.2-\mathrm{q} 23.3$ and $20 \mathrm{q} 13.12$ for most of the overlapping gained regions, and 3p21.32-p12.3, 9pter-p13.2, 17pter-p12, and 21pter-q21.1 for most of the overlapping lost areas in ER + PR- breast cancers [65].

Variations in the genomic profiles exist not only among different histopathological types of breast cancer, but are also found among the types of breast cancers of different ethnic groups. A recent study comparing breast cancer samples from African and American women has identified 6 chromosomal regions with a higher rate of

Table 1 The three subclones in an ascites fluid sample from a patient with progressive epithelial ovarian cancer

\begin{tabular}{llllll}
\hline Clone & c-myc & Rb1 & Chk2 & P53 & BRCA1 \\
\hline 1 & 4 & 2 & 5 & 2 & 4 \\
2 & 3 & 2 & 3 & 2 & 4 \\
3 & 3 & 2 & 2 & 2 & 5
\end{tabular}

Note: the numbers in Clone column indicate the coding number of the subclones; the numbers in FISH probe columns (c-myc, Rb1, Chk2, p53 and BRCA1) indicate copy numbers of each gene within a single nucleus of the cancer clone. 


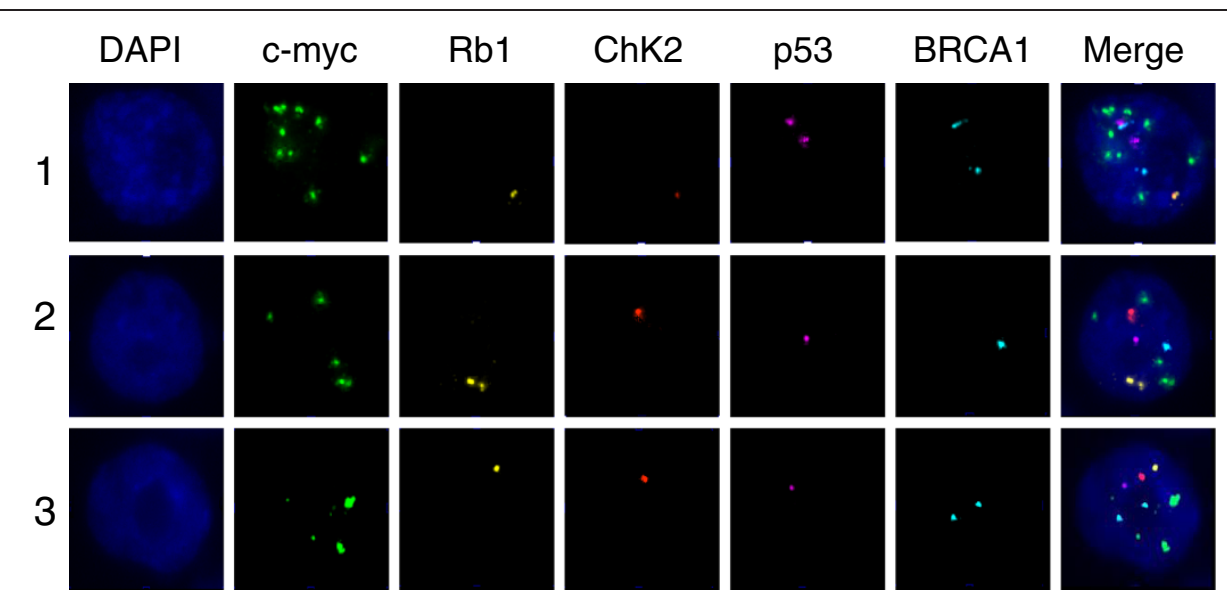

Figure 2 The three subclones obtained from a cancer stem-cell preparation for a patient with low-differentiated ovarian adenocarcinoma. BAC probes containing c-myc, Rb1, Chk2, p53 or BRCA1 were labeled with Spectrum Green, PF555 (red), PF590 (orange), HyPer5 (purple) or PF415 (blue), respectively. The mixed probes were hybridized with the cancer stem-cell preparation sample from a low-differentiated ovarian adenocarcinoma patient. The results revealed that there were three subclones showing distinct combinations of signal patterns for the five selected genes. The details of the molecular profiling are shown in Table 2.

CNAs and several candidate biomarkers that could be specific to African women [66].

Extensive screening of genomic aberrations has led to the identification of candidate biomarkers associated with breast cancer tumorigenesis, invasiveness, and metastasis, including MYC at 8q24 [67], CCND1 at 11q13 [68], Her-2 at $17 q 12$ [53], MTDH at 8q22 [69,70], and ETS transcription factors at 1q21 and 1q32 [71].

While substantial progress has been made in breast cancer genetics over the last two decades, further largescale studies integrating both genome and transcriptome analyses [72] are needed to identify the key oncogenic driver genes or other specific biomarkers. The potential new findings could be of predictive values for diagnosis, predicting metastasis, survival assessment, and guiding targeted therapy. FISH can be of particular value in both the discovery and clinical routine detection of such biomarkers and will continue to play an important role in the personalized management of breast cancer.

\section{Melanoma}

Melanoma is a heterogeneous group of melanin-producing skin malignancies with acquired genetic aberrations. Studies employing aCGH and FISH have identified a variety of recurrent chromosomal aberrations in malignant melanoma. In clinic, a small but significant part of melanocytic lesions presents with ambiguous morphologic features, and those cases are challenging to experienced dermatopathologists. Thus, a specific ancillary genetic test is needed for the initial characterization to avoid misdiagnosis and overtreatment [73,74]. Most primary melanomas exhibit either numerical or structural chromosomal abnormalities, such as deletions in 9p, 10, $6 \mathrm{q}$ and $8 \mathrm{p}$ and copy-number increase in $7,8,6 \mathrm{p}, 1 \mathrm{q}, 20$, 17 , and $2[75,76]$. Given that multiple chromosomal aberrations must be evaluated to obtain genetic profiles of melanoma, a multi-color approach comprising 4 gene probes have been adopted for a FISH-based melanoma assay [77]. The clinical studies showed that use of FISH in unambiguous cases provided promising results with relatively high sensitivity and specificity. However, the diagnostic utility of FISH in ambiguous cases remains to be determined because a standard definition of "malignancy" is yet to be established from clinical studies with large samples of ambiguous cases [78]. Furthermore, the discovery of key genomic aberrations has led to more effective targeted therapies for melanoma. For example, Vemurafenib (BRAF V600E inhibitor) and Ipilimumab (anti-CTLA4) were recently approved by the U.S. FDA and agents directed against the MAP kinase pathway (anti-MEK, anti-ERK, other anti-BRAF) are under development for

Table 2 The three subclones obtained from a cancer stem-cell preparation for a patient with low-differentiated ovarian adenocarcinoma

\begin{tabular}{llllll}
\hline Clone & c-myc & Rb1 & Chk2 & P53 & BRCA1 \\
\hline 1 & 9 & 1 & 1 & 2 & 2 \\
2 & 5 & 2 & 1 & 1 & 1 \\
3 & 4 & 1 & 1 & 1 & 2
\end{tabular}

Note: the numbers in Clone column indicate the coding number of the subclones; the numbers in FISH probe columns (c-myc, Rb1, Chk2, p53 and BRCA1) indicate copy numbers of each gene within a single nucleus of the cancer clone. 


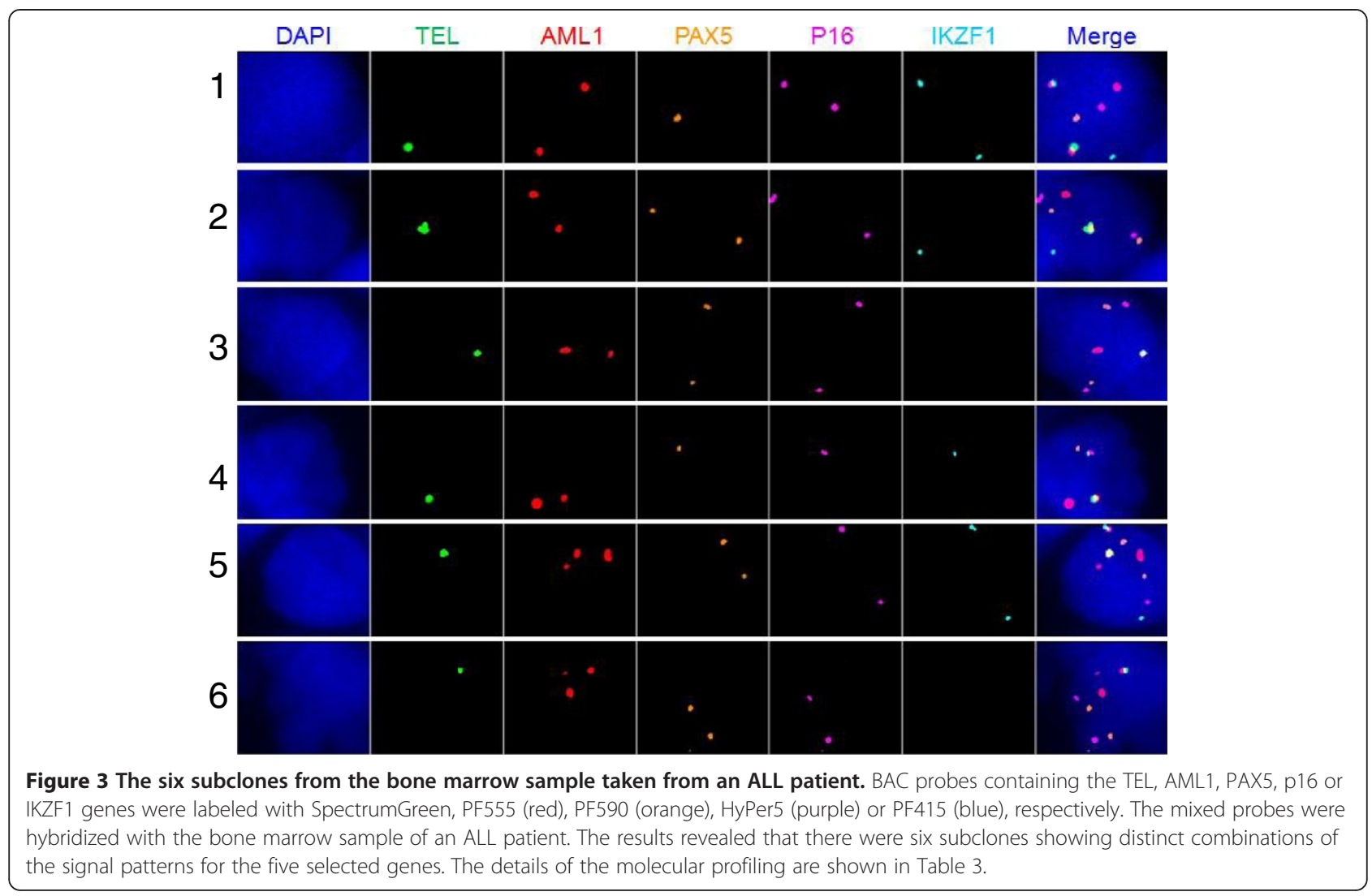

targeted therapy in cases of advanced metastatic melanoma [79].

\section{Progress in FISH methodology \\ FISH automation}

Manual evaluation of large numbers of clinical FISH samples is no doubt a time-consuming, exhausting, and error-prone procedure. Moreover, the inter-observer variability could lead to scoring inconsistency and even misdiagnosis. Thus, an automated system would greatly reduce such errors. Such an automated system is generally comprised of the following parts: a light source, filter set, objectives, signal detector, motorized scanning stage, and a computer equipped with dedicated software in charge of automated tissue-area selection, signal evaluation and data calculation [80]. There were several reports of the successful automated evaluation of HER2 gene amplification using breast cancer specimens [81-83]. An automated method has also been applied to detecting balanced rearrangements, such as the $\mathrm{BCR} / \mathrm{ABL} 1$ gene rearrangements in patients with CML [84]. Nevertheless, automated FISH is still in a premature stage with more standardization and large scale clinical trials pending.

\section{QM-FISH}

Previously, most commercial FISH detection kits contained one probe labeled with a single fluorochrome or two probes labeled with two distinct fluorochromes. These single or dual-color kits were used to detect a deletion or an amplification of a single locus-specific genomic fragment or a balanced chromosomal translocation. With the rapid progress in disease gene discoveries, there is a need to simultaneously detect multiple genes. Thus, a FISH method that employs multiple

Table 3 The six subclones from the bone marrow sample taken from an ALL patient

\begin{tabular}{lllllll}
\hline Clone & Fusion & TEL & AML1 & PAX5 & P16 & IKZF1 \\
\hline 1 & 1 & 1 & 2 & 1 & 2 & 2 \\
2 & 1 & 1 & 2 & 2 & 2 & 1 \\
3 & 1 & 1 & 2 & 2 & 2 & 0 \\
4 & 1 & 1 & 2 & 1 & 1 & 1 \\
5 & 1 & 1 & 3 & 2 & 2 & 2 \\
6 & 1 & 1 & 3 & 2 & 2 & 0
\end{tabular}

Note: the numbers in Clone column indicate the coding number of the subclones; the numbers in FISH probe columns (Fusion, TEL, AML1, PAX5, p16 and IKZF1) indicate copy numbers of each gene (or gene fusion) within a single nucleus of the cancer clone. 


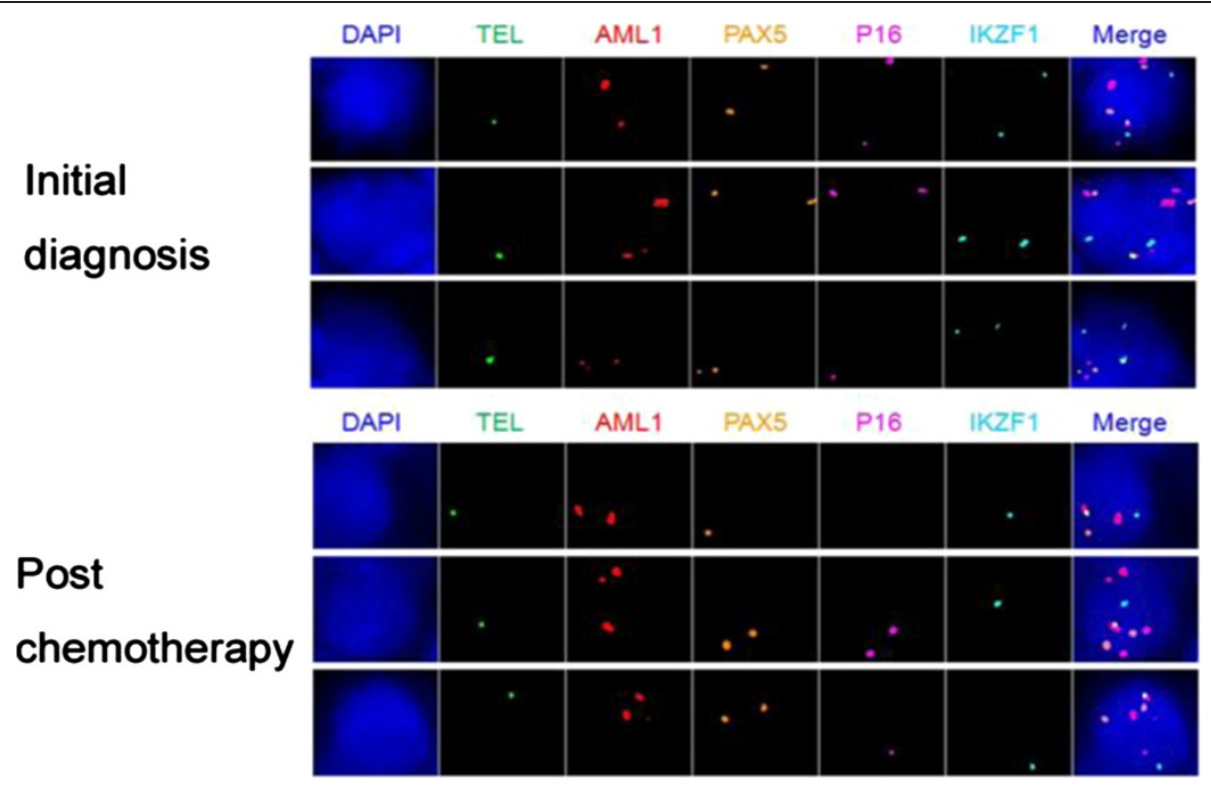

Figure 4 The clonal components of bone marrow samples taken from an ALL patient upon the initial diagnosis and after chemotherapy. BAC probes containing the TEL, AML1, PAX5, p16 or IKZF1 genes were labeled with Spectrum Green, PF555 (red), PF590 (orange), HyPer5 (purple) or PF415 (blue), respectively. The mixed probes are hybridized with the bone marrow samples upon the initial diagnosis and after thermotherapy of an ALL patient. The results revealed that there are distinct subclones upon the initial diagnosis and after chemotherapy, which showed different combinations of signal patterns for the five selected genes. The details of the molecular profiling are shown in Table 4.

probes, called quantitative multi-gene FISH (qmFISH) has recently become popular. Abbott's MultiVysion PB multi-color probe kit, a five-color FISH kit that detects chromosomes 13, 16, 18, 21 and 22 was developed to assist in preimplantation diagnosis (PGD) by polar body analysis [85]. A four-color FISH assay, targeting chromosomes $1,2,6,9,7,17$, the loci 3p24pter, and 3p13p14 has been used for the early diagnosis of renal carcinoma in biopsies of uncertain renal masses [86]. LAVysion FISH, a four-color FISH kit for simultaneously detecting chromosome 6 and the 5p15, 7p12 (EGFR gene), and 8q24 (MYC gene) loci was developed to assist in the differential diagnosis of ambiguous lung cancers [87]. In recent years, qmFISH has been used in genetic variegation and clonal evolution studies of both hematological and non-hematological cancers [88-92].

We have developed a state-of-the-art qmFISH system that can use as many as 10-20 fluorochromes, and the signals could only be analyzed by a computer-controlled detector (Zetterberg, A. et al, unpublished). This system is particularly useful for large-scale multi-gene clinical investigations of solid tumors or blood malignancies.

Currently, we are applying qmFISH to study the genetic architecture and clonal evolution in cases of ovarian cancer and leukemia. Ovarian cancer is a heterogeneous female malignancy characterized by various genomic aberrations. To define the molecular subgroups of ovarian cancer, we have chosen five genes, c-myc, Rb1, Chk2, p53 and BRCA1, which are known to be associated with the pathogenesis of ovarian cancer. The ascites fluid samples were collected from ovarian cancer patients from Tianjin Medical University Cancer Institute and Hospital from January to December 2012, with hospital ethical review committee approval. The ovarian cancer cell sections were prepared by Cytospin procedure and fixed overnight in methanol. qmFISH was performed as previously described [93]. In each case, at least 200 nuclei were scored for CNAs (copy number alterations) of c-myc, Rb1, Chk2, p53 and BRCA1. The results showed that an ascites fluid cytospin sample from a representative case of progressive epithelial ovarian cancer contained at least three subclones with distinct molecular profiles for the selected genes (Figure 1 and Table 1). Furthermore, a CD133 + ALDH + cancer stem cell [94,95]

Table 4 The clonal components of bone marrow samples taken from an ALL patient upon the initial diagnosis and post chemotherapy

\begin{tabular}{lllllll}
\hline Clone & Fusion & TEL & AML1 & PAX5 & P16 & IKZF1 \\
\hline Initial diagnosis & 1 & 1 & 2 & 2 & 2 & 2 \\
& 1 & 1 & 3 & 2 & 2 & 2 \\
Post chemotherapy & 1 & 1 & 2 & 1 & 0 & 1 \\
& 1 & 1 & 3 & 2 & 2 & 1 \\
& 1 & 1 & 3 & 2 & 1 & 1 \\
\hline
\end{tabular}

Note: the numbers in FISH probe columns (Fusion, TEL, AML1, PAX5, p16 and IKZF1) indicate copy numbers of each gene (or gene fusion) within a single nucleus of the cancer clone. 


\begin{tabular}{|c|c|c|c|c|c|}
\hline Probes & $\begin{array}{l}\text { Cytogenetic } \\
\text { anomaly }\end{array}$ & Associated disorders & P53 (17p13.1) & $\operatorname{del}(17)(p 13.1)$ & $\mathrm{ALL}, \mathrm{AML}, \mathrm{CLD}, \mathrm{MDS}, \mathrm{NHL}$ \\
\hline $\mathrm{BCR} / \mathrm{ABL}$ & $\mathrm{t}(9 ; 22)(\mathrm{q} 34 ; \mathrm{q} 11)$ & $\begin{array}{l}\text { CML, ALL, AML-M1, AML-M2, } \\
\text { MPD }\end{array}$ & IGH (14q32) & del(14q32) & $\begin{array}{l}\mathrm{CLL} \\
\mathrm{CLD}, \mathrm{NHL}\end{array}$ \\
\hline PML/RARa & $t(15 ; 17)(q 22 ; q 21)$ & AML-M3, CML Ph+ & & $\mathrm{t}(2 ; 14)(\mathrm{p} 13 ; q 32)$ & $\mathrm{B}-\mathrm{CLL}$ \\
\hline AML1/ETO & $\mathrm{t}(8 ; 21)(\mathrm{q} 22 ; \mathrm{q} 22)$ & AML-M2, AML-M4, MDS & & $\mathrm{t}(3 ; 14)(\mathrm{q} 27 ; \mathrm{q} 32)$ & $\mathrm{DLCL}, \mathrm{FL}$ \\
\hline \multirow[t]{11}{*}{ MLL (11q23) } & $t(1 ; 11)(p 32 ; q 23)$ & $A L L, A M L$ & & $t(4 ; 14)(p 13 ; q 32)$ & MM \\
\hline & $\mathrm{t}(1 ; 11)(\mathrm{q} 21 ; \mathrm{q} 23)$ & AML-M4, AML-M5 & & $\mathrm{t}(5 ; 14)(\mathrm{q} 31 ; \mathrm{q} 32)$ & ALL \\
\hline & $\mathrm{t}(2 ; 11)(\mathrm{p} 21 ; \mathrm{q} 23)$ & MDS & & $\mathrm{t}(6 ; 14)(\mathrm{p} 25 ; \mathrm{q} 32)$ & MM \\
\hline & $\mathrm{t}(4 ; 11)(\mathrm{q} 21 ; \mathrm{q} 23)$ & $A L L, A M L$ & & $\mathrm{t}(8 ; 14)(\mathrm{q} 24 ; \mathrm{q} 32)$ & ALL \\
\hline & $\mathrm{t}(6 ; 11)(\mathrm{q} 27 ; \mathrm{q} 23)$ & AML-M4, AMI-M5 & & $\mathrm{t}(9 ; 14)(\mathrm{p} 12-13 ; q 32)$ & $\mathrm{B}-\mathrm{NHL}, \mathrm{LPL}$ \\
\hline & $\mathrm{t}(9 ; 11)(\mathrm{p} 22 ; \mathrm{q} 23)$ & ALL, AML-M5, MDS, t-MDS & & $t(11 ; 14)(q 13 ; q 32)$ & B-PLL, CLD, MM, MCL, MGUS, NHL \\
\hline & $t(10 ; 11)(p 13 ; q 23)$ & AML-M4, AMI-M5 & & $t(14 ; 16)(q 32 ; q 23)$ & MM \\
\hline & $t(11 ; 17)(q 23 ; q 21)$ & AML-M3, AML-M4, AMI-M5 & & $t(14 ; 18)(q 32 ; q 21)$ & $\mathrm{CLD}, \mathrm{FL}, \mathrm{DLCL}, \mathrm{MM}, \mathrm{NHL}$ \\
\hline & $t(11 ; 19)(q 23 ; p 13)$ & ALL, AML-M4, AML-M5, t-AMI & & $t(14 ; 19)(q 32 ; q 13)$ & $\mathrm{CLD}, \mathrm{CLL}, \mathrm{NHL}$ \\
\hline & $t(X ; 11)(q 13 ; q 23)$ & T-ALL & & $t(14 ; 22)(q 32 ; q 11)$ & ALL \\
\hline & del(11q23) & $\mathrm{AML}, \mathrm{ALL}, \mathrm{CLD}, \mathrm{CLL}, \mathrm{MDS}, \mathrm{NHL}$ & ATM (11q22.3) & del(11)(q13q14-q23) & $\mathrm{AML}, \mathrm{CLD}, \mathrm{CLL}, \mathrm{MDS}, \mathrm{NHL}$ \\
\hline \multirow[t]{3}{*}{ CBFB (16q22) } & $t(16 ; 16)(p 13 ; q 22)$ & AML-M4Eo, MDS & FGFR3/IGH & $t(4 ; 14)(p 13 ; q 32)$ & MM \\
\hline & $\operatorname{inv}(16)(p 13 q 22)$ & AML-M4EO & $\mathrm{MAF} / \mathrm{IGH}$ & $t(14 ; 16)(q 32 ; q 23)$ & MM \\
\hline & del(16q22) & AML, AML-M4Eo, NHL & CCND1/IGH & $t(11 ; 14)(q 13 ; q 32)$ & B-PLL, CLD, MM, MCL, MGUS, NHL \\
\hline \multirow[t]{3}{*}{ EVI1 (3q26) } & $t(3 ; 3)(q 21 ; q 26)$ & AML, MDS & CEP12 & +12 & $\mathrm{AML}, \mathrm{CLL}, \mathrm{CLD}, \mathrm{NHL}$ \\
\hline & $\operatorname{inv}(3)(q 21 q 26)$ & AML-M4, AML-M6, CML Ph+, MDS & BCL6 (3q27) & $\mathrm{t}(3 ; 14)(\mathrm{q} 27 ; \mathrm{q} 32)$ & $\mathrm{DLCL}, \mathrm{FL}$ \\
\hline & $\mathrm{t}(3 ; 21)(\mathrm{q} 26 ; \mathrm{q} 22)$ & $\mathrm{AML}, \mathrm{CML} \mathrm{Ph}+, \mathrm{MDS}$ & & $\mathrm{t}(3 ; 22)(\mathrm{q} 27 ; \mathrm{q} 11)$ & $\mathrm{DLCL}, \mathrm{FL}$ \\
\hline \multirow{2}{*}{$\begin{array}{l}\text { FGFR1/D8Z2 } \\
(8 p 11)\end{array}$} & $\mathrm{t}(8 ; 13)(\mathrm{p} 11 ; \mathrm{q} 12)$ & MPD & $\mathrm{BCL} 2(18 \mathrm{q} 21)$ & $t(11 ; 18)(q 21 ; q 21)$ & $M Z L, N H L$ \\
\hline & $\mathrm{t}(8 ; 16)(\mathrm{p} 11 ; \mathrm{p} 13)$ & AML-M4, AML-M5 & & $t(14 ; 18)(q 32 ; q 21)$ & $\mathrm{CLD}, \mathrm{FL}, \mathrm{DLCL}, \mathrm{MM}, \mathrm{NHL}$ \\
\hline TEL/AML1 & $t(12 ; 21)(p 13 ; q 22)$ & ALL & & del(18)(q21) & $\mathrm{AML}, \mathrm{CLD}, \mathrm{NHL}$ \\
\hline TCF3/PBX1 & $\mathrm{t}(1 ; 19)(\mathrm{q} 23 ; \mathrm{p} 13)$ & pre-B ALL & & -18 & CLD \\
\hline \multirow{3}{*}{$\begin{array}{l}\text { CKS1B }(1 q 21) / \\
\text { CDKN2C (1p32) }\end{array}$} & $\operatorname{dup}(1)(q 21 q 32)$ & $\mathrm{ALL}, \mathrm{CLD}, \mathrm{NHL}$ & & +18 & $\mathrm{ALL}, \mathrm{CLD}$ \\
\hline & $\operatorname{del}(1)(q 21)$ & $\mathrm{NHL}$ & CEPX/Y & $X Y / X X$ & ALLO-SCT \\
\hline & $\begin{array}{l}\text { del(1)(p32p36) } \\
t(2: 8)(p 12: q 24)\end{array}$ & $\begin{array}{l}C L D, N H L \\
A L L-L 3, B L, N H L\end{array}$ & & $-Y$ & $\begin{array}{l}\text { ALL, AML, CLD, MDS, MM, MPD, } \\
\text { NHL, PV }\end{array}$ \\
\hline
\end{tabular}

Table 5 FISH probes that are commonly used for clinical diagnosis of hematological diseases

\begin{tabular}{|c|c|c|}
\hline & $\mathrm{t}(8 ; 14)(\mathrm{q} 24 ; \mathrm{q} 32)$ & ALL-L3, BL, MM, NHL \\
\hline & $\mathrm{t}(8 ; 14)(\mathrm{q} 24 ; \mathrm{q} 11)$ & T-ALL \\
\hline & $\mathrm{t}(8 ; 22)(\mathrm{q} 24 ; \mathrm{q} 11)$ & $A L L-L 3, B L$ \\
\hline CEP8 & +8 & ALL, AML, CLD, MPD, MDS, PV \\
\hline \multirow{2}{*}{$\begin{array}{l}\text { EGR1 (5q31)/ } \\
\text { D5S721 (5p15.2) }\end{array}$} & -5 & AML, MDS \\
\hline & $\operatorname{del}(5)(q 13 q 33)$ & AML, MDS, MPD, 5q- syn \\
\hline \multirow{3}{*}{$\begin{array}{l}\text { D7S486 (7q31)/ } \\
\text { CEP7 } \\
\text { (7p11.1-7q11.1) }\end{array}$} & -7 & AML, MDS, MPD \\
\hline & $\operatorname{del}(7)(q 11)$ & $\mathrm{ALL}, \mathrm{AML}, \mathrm{MDS}$ \\
\hline & $\operatorname{del}(7)(q 22 q 34)$ & $\mathrm{AML}, \mathrm{CLD}, \mathrm{CMD}, \mathrm{MDS}, \mathrm{NHL}$ \\
\hline \multirow{2}{*}{$\begin{array}{l}\text { D20S108 } \\
(20 q 12)\end{array}$} & $\operatorname{del}(20)(q 11 q 13)$ & $\mathrm{AML}, \mathrm{CMD}, \mathrm{MDS}, \mathrm{PV}$ \\
\hline & -20 & ALL \\
\hline \multirow[t]{2}{*}{ RB-1 (13q14) } & del(13)(q12-q22) & $\begin{array}{l}\mathrm{AML}, \mathrm{AMM}, \mathrm{CLD}, \mathrm{CLL}, \mathrm{MM}, \mathrm{MDS} \text {, } \\
\mathrm{NHL}\end{array}$ \\
\hline & del(13)(q12-q14) & AML, AMM, CLD, MDS, NHL \\
\hline
\end{tabular}

Table 5 FISH probes that are commonly used for clinical diagnosis of hematological diseases (Continued)

preparation isolated from a case of low-differentiated ovarian adenocarcinoma included three subclones with distinct qmFISH fingerprints (Figure 2 and Table 2). Thus, qmFISH analysis appears to be an excellent tool for molecular profiling of ovarian cancer at the single cell level.

Another of our projects is to apply qmFISH to molecular profiling of acute lymphatic leukemia (ALL). It has been reported that $t(12 ; 21)$ leads to fusion of an almost complete RUNX1(AML1) protein to part of the ETV6 (TEL) protein, which is found in $20-25 \%$ of the ALL patients. The ALL patients with the ETV6 (TEL)/ RUNX1(AML1) translocation generally have a better clinical outcome, but are more likely to experience a recurrence. The deletion of ETV6 (TEL) gene, which is associated with the ETV6 (TEL)/RUNX1(AML1) translocation, is common in ALL and leads to $\mathrm{LOH}$ of 
Table 6 FISH probes that are commonly used for clinical diagnosis of solid tumors

\begin{tabular}{lll}
\hline Probes & $\begin{array}{l}\text { Cytogenetic } \\
\text { anomaly }\end{array}$ & $\begin{array}{l}\text { Associated } \\
\text { disorder }\end{array}$ \\
\hline CEP3,7,17; p16 & $\begin{array}{l}\text { Chromosome 3, 7, 17 } \\
\text { aneuploidy; 9p21 }\end{array}$ & Bladder carcinoma \\
HER-2/CEP17 & $17 q 11.2-q 12$ & Breast cancer \\
TOP2A & $17 q 21-22$ & Breast cancer \\
TERC/CEP3 & $3 q 26.3$ & Cervical cancer \\
EWSR1 & $22 q 12$ & Ewing sarcoma \\
EGFR & $7 p 12$ & NSCLC \\
ALK & $2 p 23$ & NSCLC \\
ROS1 & $6 p 22$ & NSCLC \\
TMPRSS2/ETV1 & $21 q 22.3 / 7 p 21.1$ & Prostate cancer \\
TMPRSS2/ETV4 & $21 q 22.3 / 17 q 21.3$ & Prostate cancer \\
ERG & $21 q 22.2$ & Prostate cancer \\
\hline
\end{tabular}

12p12-13. In addition to ETV6 (TEL) and RUNX1 (AML1), we selected PAX5, CDKN2A(P16) and IKZF, which are known to be associated with ALL pathogenesis, as target genes for the molecular profiling $[88,96]$. The bone marrow (BM) samples were collected from the ETV6 (TEL)/RUNX1(AML1) positive ALL patients from Tianjin Blood Diseases Hospital from January to December 2012, with hospital ethical review committee approval. The BM mononuclear cells were fixed in methanol:acetic acid solution. qmFISH was performed as previously described [93]. In each case, at least $200 \mathrm{nu}$ clei were scored for the presence of the ETV6 (TEL)/ RUNX1(AML1) fusion gene in combination with CNAs of ETV6 (TEL), RUNX1(AML1), PAX5, CDKN2A(p16) and IKZF. The results showed that the bone marrow sample of a representative case of ALL contained at least 6 subclones with distinct combinations of molecular patterns of the five selected genes (Figure 3 and Table 3). The qmFISH studies have also been successfully used to compare the clonal components of bone marrow samples taken from the same ALL patient upon the initial diagnosis and post chemotherapy, which demonstrated a clonal evolution phenomenon (Figure 4 and Table 4). Taken together, our results showed that qmFISH is a useful tool for analyzing the genetic architecture and clonal evolution of leukemia cells, which could provide important information for monitoring the disease process and appropriately selecting the therapy.

\section{Concluding remarks}

While high-resolution molecular profiling techniques such as aCGH, SNP array analysis and whole-genome sequencing play critical roles in identifying novel chromosomal abnormalities, they are not practical for a routine application of clinical diagnosis due to various reasons. In contrast, FISH continues to work as a cornerstone in genetic labs due to its specificity, simplicity and reliability. Given the theory that cancer may be derived from tumor stem cells [97], the genetic abnormalities detected by FISH are likely to represent the initial or crucial genetic lesions responsible for cancer at the stem-cell level. Currently, FISH is widely used for detecting specific genomic aberrations, providing important information for disease diagnosis, risk stratification and prognosis (Tables 5 and 6). Furthermore, FISH is the gold standard for evaluating some key biomarkers, such as BCR/ABL1, HER2 and ALK rearrangements, and plays a critical role in guiding targeted therapies. In conclusion, FISH has evolved to become a vital diagnostic tool for personalized medicine.

\section{Abbreviations \\ FISH: Fluorescence in situ hybridization; CC: Conventional cytogenetics; aCGH: Array-based comparative genomic hybridization; SNP-arrays: Single} nucleotide polymorphism arrays; CNAs: Copy number alterations.

\section{Competing interests}

All authors declare that they have no conflicts of interests.

\section{Authors' contributions}

WM and KR wrote the article; $L H, L Z, Y H, X Z, H L$ and WM were involved in qmFISH research; $A Z$ and $T C$ reviewed the article. All authors read and approved the final manuscript.

\section{Acknowledgement}

This work was supported by research grants from the Ministry of Science and Technology of China (2010DFB30270, 2011ZX09102-010-04, 2013BAI01B09), National Natural Science Foundation (81370598), the Tianjin Science and Technology Commission (09ZCZDSF03800, 11JCZDJC27900) and Jiangsu Nantong Science and Technology Commission (AS2013007).

\section{Author details}

${ }^{1}$ State Key Laboratory of Experimental Hematology, Institute of Hematology and Blood Diseases Hospital, Chinese Academy of Medical Sciences and Peking Union Medical College, Tianjin, China. ²Department of Pathology, Institute of Hematology and Blood Diseases Hospital, Chinese Academy of Medical Sciences and Peking Union Medical College, Tianjin, China.

${ }^{3}$ Department of Pediatrics, Institute of Hematology and Blood Diseases Hospital, Chinese Academy of Medical Sciences and Peking Union Medical College, Tianjin, China. ${ }^{4}$ Tianjin Medical University Cancer Institute and Hospital, National Clinical Research Center of Cancer, Tianjin, China. ${ }^{5}$ Department of Oncology-Pathology and Karolinska Cancer Center, Karolinska Institute, Stockholm, Sweden. ${ }^{6}$ Center for Stem Cell Medicine, Chinese Academy of Medical Sciences and Peking Union Medical College, Nanjing Road 288, Tianjin 300020, P.R. China.

Received: 16 November 2013 Accepted: 30 January 2014

Published: 5 February 2014

\section{References}

1. Wertheim GB, Hexner E, Bagg A: Molecular-based classification of acute myeloid leukemia and its role in directing rational therapy: personalized medicine for profoundly promiscuous proliferations. Mol Diagn Ther 2012, 16(6):357-369.

2. Landau DA, Wu CJ: Chronic lymphocytic leukemia: molecular heterogeneity revealed by high-throughput genomics. Genome Med 2013, 5(5):47.

3. Dietel M, Johrens K, Laffert M, Hummel M, Blaker H, Muller BM, Lehmann A, Denkert C, Heppner FL, Koch A, et al: Predictive molecular pathology and its role in targeted cancer therapy: a review focussing on clinical relevance. Cancer Gene Ther 2013, 20(4):211-221. 
4. Boyd C, Boyle DP: Molecular diagnosis on tissues and cells: how it affects training and will affect practice in the future. Cytopathology 2012, 23(5):286-294.

5. Jiang $H$, Xue $Y$, Wang Q, Pan J, Wu Y, Zhang J, Bai S, Wang Q, He G, Sun A, et al: The utility of fluorescence in situ hybridization analysis in diagnosing myelodysplastic syndromes is limited to cases with karyotype failure. Leuk Res 2012, 36(4):448-452.

6. Pathmanathan N, Bilous AM: HER2 testing in breast cancer: an overview of current techniques and recent developments. Pathology 2012 , 44(7):587-595

7. Kim HR, Lim SM, Kim HJ, Hwang SK, Park JK, Shin E, Bae MK, Ou SH, Wang J, Jewell SS, et al: The frequency and impact of ROS1 rearrangement on clinical outcomes in never smokers with lung adenocarcinoma. Ann Oncol 2013, 24(9):2364-2370.

8. Casaluce F, Sgambato A, Maione P, Rossi A, Ferrara C, Napolitano A, Palazzolo G, Ciardiello F, Gridelli C: ALK inhibitors: a new targeted therapy in the treatment of advanced NSCLC. Target Oncol 2013, 8(1):55-67.

9. Gandhi L, Janne PA: Crizotinib for ALK-rearranged non-small cell lung cancer: a new targeted therapy for a new target. Clin Cancer Res 2012, 18(14):3737-3742.

10. Rowley JD: Letter: A new consistent chromosomal abnormality in chronic myelogenous leukaemia identified by quinacrine fluorescence and Giemsa staining. Nature 1973, 243(5405):290-293.

11. Zhang Y, Rowley JD: Chronic myeloid leukemia: current perspectives. Clin Lab Med 2011, 31(4):687-698. x.

12. Latagliata R, Avvisati G, Lo Coco F, Petti MC, Diverio D, Spadea A, Fazi P, Torromeo C, Breccia M, Malagnino F, et al: The role of all-trans-retinoic acid (ATRA) treatment in newly-diagnosed acute promyelocytic leukemia patients aged $>60$ years. Ann Oncol 1997, 8(12):1273-1275.

13. Ablain J, de The H: Revisiting the differentiation paradigm in acute promyelocytic leukemia. Blood 2011, 117(22):5795-5802.

14. Costa D, Vidal A, Carrio A, Munoz C, Arias A, Gomez C, Berneaga D, Colomer D, Rozman M, Pratcorona M, et al: Refining the diagnosis and prognostic categorization of acute myeloid leukemia patients with an integrated use of cytogenetic and molecular studies. Acta Haemato/ 2013, 129(2):65-71.

15. Smith ML, Hills RK, Grimwade D: Independent prognostic variables in acute myeloid leukaemia. Blood Rev 2011, 25(1):39-51.

16. Ritterbach J, Hiddemann W, Beck JD, Schrappe M, Janka-Schaub G, Ludwig WD, Harbott J, Lampert F: Detection of hyperdiploid karyotypes (>50 chromosomes) in childhood acute lymphoblastic leukemia (ALL) using fluorescence in situ hybridization (FISH). Leukemia 1998, 12(3):427-433.

17. Lampert F, Harbott J, Borkhardt A: Cytogenetic aspects of childhood leukemias. Klin Padiatr 2013, 225(Suppl 1):S30-S33.

18. Smoley SA, Brockman SR, Paternoster SF, Meyer RG, Dewald GW: A novel tricolor, dual-fusion fluorescence in situ hybridization method to detect $B C R / A B L$ fusion in cells with $t(9 ; 22)(q 34 ; q 11.2)$ associated with deletion of DNA on the derivative chromosome 9 in chronic myelocytic leukemia. Cancer Genet Cytogenet 2004, 148(1):1-6.

19. Dohner H, Stilgenbauer S, Benner A, Leupolt E, Krober A, Bullinger L, Dohner K, Bentz M, Lichter P: Genomic aberrations and survival in chronic lymphocytic leukemia. N Engl J Med 2000, 343(26):1910-1916.

20. Rodriguez-Vicente AE, Diaz MG, Hernandez-Rivas JM: Chronic lymphocytic leukemia: a clinical and molecular heterogenous disease. Cancer genetics 2013, 206(3):49-62.

21. Rosenquist R, Cortese D, Bhoi S, Mansouri L, Gunnarsson R: Prognostic markers and their clinical applicability in chronic lymphocytic leukemia: where do we stand? Leuk Lymphoma 2013, 54(11):2351-2364.

22. Hallek M, Fischer K, Fingerle-Rowson G, Fink AM, Busch R, Mayer J, Hensel M, Hopfinger G, Hess G, von Grunhagen U, et al: Addition of rituximab to fludarabine and cyclophosphamide in patients with chronic lymphocytic leukaemia: a randomised, open-label, phase 3 trial. Lancet 2010, 376(9747):1164-1174.

23. Nilsson T, Hoglund M, Lenhoff S, Rylander L, Turesson I, Westin J, Mitelman F, Johansson B: A pooled analysis of karyotypic patterns, breakpoints and imbalances in 783 cytogenetically abnormal multiple myelomas reveals frequently involved chromosome segments as well as significant age- and sex-related differences. Brit J Haematol 2003, 120(6):960-969.

24. Gutierrez NC, Garcia JL, Hernandez JM, Lumbreras E, Castellanos M, Rasillo A, Mateo G, Hernandez JM, Perez S, Orfao A, et al: Prognostic and biologic significance of chromosomal imbalances assessed by comparative genomic hybridization in multiple myeloma. Blood 2004, 104(9):2661-2666.
25. Smadja NV, Bastard C, Brigaudeau C, Leroux D, Fruchart C, Groupe Francais de Cytogenetique $\mathrm{H}$ : Hypodiploidy is a major prognostic factor in multiple myeloma. Blood 2001, 98(7):2229-2238.

26. Sawyer JR: The prognostic significance of cytogenetics and molecular profiling in multiple myeloma. Cancer Genet 2011, 204(1):3-12.

27. Kuehl WM, Bergsagel PL: Multiple myeloma: evolving genetic events and host interactions. Nat Rev Cancer 2002, 2(3):175-187.

28. Bergsagel PL, Kuehl WM: Chromosome translocations in multiple myeloma. Oncogene 2001, 20(40):5611-5622.

29. Avet-Loiseau H, Gerson F, Magrangeas F, Minvielle S, Harousseau JL, Bataille R, Intergroupe Francophone du M: Rearrangements of the c-myc oncogene are present in $15 \%$ of primary human multiple myeloma tumors. Blood 2001, 98(10):3082-3086.

30. Tricot G, Barlogie B, Jagannath S, Bracy D, Mattox S, Vesole DH, Naucke S, Sawyer JR: Poor prognosis in multiple myeloma is associated only with partial or complete deletions of chromosome 13 or abnormalities involving $11 \mathrm{q}$ and not with other karyotype abnormalities. Blood 1995, 86(11):4250-4256.

31. Fonseca R, Oken MM, Harrington D, Bailey RJ, Van Wier SA, Henderson KJ, Kay NE, Van Ness B, Greipp PR, Dewald GW: Deletions of chromosome 13 in multiple myeloma identified by interphase FISH usually denote large deletions of the q arm or monosomy. Leukemia 2001, 15(6):981-986.

32. Drach J, Ackermann J, Fritz E, Kromer E, Schuster R, Gisslinger H, DeSantis M, Zojer N, Fiegl M, Roka S, et al: Presence of a p53 gene deletion in patients with multiple myeloma predicts for short survival after conventional-dose chemotherapy. Blood 1998, 92(3):802-809.

33. Fonseca R, Blood E, Rue M, Harrington D, Oken MM, Kyle RA, Dewald GW, Van Ness B, Van Wier SA, Henderson KJ, et al: Clinical and biologic implications of recurrent genomic aberrations in myeloma. Blood 2003, 101(11):4569-4575.

34. Qazilbash MH, Saliba RM, Ahmed B, Parikh G, Mendoza F, Ashraf N, Hosing C, Flosser T, Weber DM, Wang M, et al: Deletion of the short arm of chromosome 1 (del $1 \mathrm{p}$ ) is a strong predictor of poor outcome in myeloma patients undergoing an autotransplant. Biol Blood Marrow Transplant 2007, 13(9):1066-1072

35. Wu KL, Beverloo B, Lokhorst HM, Segeren CM, van der Holt B, Steijaert MM, Westveer PH, Poddighe PJ, Verhoef GE, Sonneveld P, et al: Abnormalities of chromosome $1 p / q$ are highly associated with chromosome $13 / 13 q$ deletions and are an adverse prognostic factor for the outcome of high-dose chemotherapy in patients with multiple myeloma. Brit $J$ Haematol 2007, 136(4):615-623.

36. Shaughnessy JD Jr, Zhan F, Burington BE, Huang Y, Colla S, Hanamura I, Stewart JP, Kordsmeier B, Randolph C, Williams DR, et al: A validated gene expression model of high-risk multiple myeloma is defined by deregulated expression of genes mapping to chromosome 1. Blood 2007, 109(6):2276-2284.

37. Kawankar N, Jijina F, Ghosh K, Vundinti BR: Cytogenetic and comparative genomic hybridization study of Indian myelodysplastic syndromes. Cancer Epidemiol 2011, 35(4):e1-e5.

38. Voso MT, Fenu S, Latagliata R, Buccisano F, Piciocchi A, Aloe-Spiriti MA, Breccia M, Criscuolo M, Andriani A, Mancini S, et al: Revised International Prognostic Scoring System (IPSS) predicts survival and leukemic evolution of myelodysplastic syndromes significantly better than IPSS and WHO prognostic scoring system: validation by the Gruppo Romano Mielodisplasie Italian Regional Database. J Clin Oncol 2013, 31(21):2671-2677.

39. Adema V, Hernandez JM, Abaigar M, Lumbreras E, Such E, Calull A, Dominguez E, Arenillas L, Mallo M, Cervera J, et al: Application of FISH 7q in MDS patients without monosomy 7 or $7 q$ deletion by conventional G-banding cytogenetics: does $-7 / 7 q$ - detection by FISH have prognostic value? Leuk Res 2013, 37(4):416-421

40. Itzykson R, Kosmider O, Cluzeau T, Mansat-De Mas V, Dreyfus F, Beyne-Rauzy O, Quesnel B, Vey N, Gelsi-Boyer V, Raynaud S, et al: Impact of TET2 mutations on response rate to azacitidine in myelodysplastic syndromes and low blast count acute myeloid leukemias. Leukemia 2011, 25(7):1147-1152.

41. Otrock ZK, Tiu RV, Maciejewski JP, Sekeres MA: The need for additional genetic markers for myelodysplastic syndrome stratification: what does the future hold for prognostication? Expert Rev Hematol 2013, 6(1):59-68.

42. Weickhardt AJ, Aisner DL, Franklin WA, Varella-Garcia M, Doebele RC, Camidge DR: Diagnostic assays for identification of anaplastic lymphoma kinase-positive non-small cell lung cancer. Cancer 2013, 119(8):1467-1477. 
43. Gainor JF, Varghese AM, Ou SH, Kabraji S, Awad MM, Katayama R, Pawlak A, Mino-Kenudson M, Yeap BY, Riely GJ, et al: ALK rearrangements are mutually exclusive with mutations in EGFR or KRAS: an analysis of 1,683 patients with non-small cell lung cancer. Clin Cancer Res 2013, 19(15):4273-4281.

44. Savic $S$, Bubendorf $L$ : Role of fluorescence in situ hybridization in lung cancer cytology. Acta Cytol 2012, 56(6):611-621.

45. Yoshida A, Kohno T, Tsuta K, Wakai S, Arai Y, Shimada Y, Asamura H, Furuta K, Shibata T, Tsuda H: ROS1-rearranged lung cancer: a clinicopathologic and molecular study of 15 surgical cases. Am J Surg Pathol 2013, 37(4):554-562.

46. Rothschild SI, Gautschi O: Crizotinib in the treatment of non-small-cell lung cancer. Clin Lung Cancer 2013, 14(5):473-480.

47. Mosquera JM, Mehra R, Regan MM, Perner S, Genega EM, Bueti G, Shah RB, Gaston S, Tomlins SA, Wei JT, et al: Prevalence of TMPRSS2-ERG fusion prostate cancer among men undergoing prostate biopsy in the United States. Clin Cancer Res 2009, 15(14):4706-4711.

48. Attard G, Clark J, Ambroisine L, Fisher G, Kovacs G, Flohr P, Berney D, Foster CS, Fletcher A, Gerald WL, et al: Duplication of the fusion of TMPRSS2 to ERG sequences identifies fatal human prostate cancer. Oncogene 2008, 27(3):253-263.

49. Demichelis F, Fall K, Perner S, Andren O, Schmidt F, Setlur SR, Hoshida Y, Mosquera JM, Pawitan Y, Lee C, et al: TMPRSS2:ERG gene fusion associated with lethal prostate cancer in a watchful waiting cohort. Oncogene 2007, 26(31):4596-4599.

50. Gopalan A, Leversha MA, Satagopan JM, Zhou Q, Al-Ahmadie HA, Fine SW Eastham JA, Scardino PT, Scher HI, Tickoo SK, et al: TMPRSS2-ERG gene fusion is not associated with outcome in patients treated by prostatectomy. Cancer Res 2009, 69(4):1400-1406.

51. Saramaki OR, Harjula AE, Martikainen PM, Vessella RL, Tammela TL, Visakorpi T: TMPRSS2:ERG fusion identifies a subgroup of prostate cancers with a favorable prognosis. Clin Cancer Res 2008, 14(11):3395-3400.

52. van de Vijver $M$, van de Bersselaar $R$, Devilee $P$, Cornelisse $C$, Peterse J, Nusse R: Amplification of the neu (c-erbB-2) oncogene in human mammmary tumors is relatively frequent and is often accompanied by amplification of the linked c-erbA oncogene. Mol Cell Bio/ 1987, 7(5):2019-2023.

53. Slamon DJ, Godolphin W, Jones LA, Holt JA, Wong SG, Keith DE, Levin WJ, Stuart SG, Udove J, Ullrich A, et al: Studies of the HER-2/neu proto-oncogene in human breast and ovarian cancer. Science 1989, 244(4905):707-712.

54. Menard S, Fortis S, Castiglioni F, Agresti R, Balsari A: HER2 as a prognostic factor in breast cancer. Oncology 2001, 61(Suppl 2):67-72.

55. Rouzier R, Perou CM, Symmans WF, Ibrahim N, Cristofanilli M, Anderson K, Hess KR, Stec J, Ayers M, Wagner P, et al: Breast cancer molecular subtypes respond differently to preoperative chemotherapy. Clin Cancer Res 2005, 11(16):5678-5685.

56. Cleator S, Ashworth A: Molecular profiling of breast cancer: clinical implications. Brit J Cancer 2004, 90(6):1120-1124.

57. Perou CM, Sorlie T, Eisen MB, van de Rijn M, Jeffrey SS, Rees CA, Pollack JR, Ross DT, Johnsen H, Akslen LA, et al: Molecular portraits of human breast tumours. Nature 2000, 406(6797):747-752.

58. Sorlie T, Perou CM, Tibshirani R, Aas T, Geisler S, Johnsen H, Hastie T, Eisen $M B$, van de Rijn $M$, Jeffrey SS, et al: Gene expression patterns of breast carcinomas distinguish tumor subclasses with clinical implications. Proc Natl Acad Sci USA 2001, 98(19):10869-10874

59. Hicks J, Krasnitz A, Lakshmi B, Navin NE, Riggs M, Leibu E, Esposito D, Alexander J, Troge J, Grubor V, et al: Novel patterns of genome rearrangement and their association with survival in breast cancer. Genome Res 2006, 16(12):1465-1479.

60. Chin K, DeVries S, Fridlyand J, Spellman PT, Roydasgupta R, Kuo WL, Lapuk A, Neve RM, Qian Z, Ryder T, et al: Genomic and transcriptional aberrations linked to breast cancer pathophysiologies. Cancer Cell 2006, 10(6):529-541.

61. Fridlyand J, Snijders AM, Ylstra B, Li H, Olshen A, Segraves R, Dairkee S, Tokuyasu T, Ljung BM, Jain AN, et al: Breast tumor copy number aberration phenotypes and genomic instability. BMC Cancer 2006, 6:96.

62. Bergamaschi A, Kim YH, Wang P, Sorlie T, Hernandez-Boussard T, Lonning PE, Tibshirani R, Borresen-Dale AL, Pollack JR: Distinct patterns of DNA copy number alteration are associated with different clinicopathological features and gene-expression subtypes of breast cancer. Gene Chromosome Canc 2006, 45(11):1033-1040.

63. Letessier A, Sircoulomb F, Ginestier C, Cervera N, Monville F, Gelsi-Boyer V, Esterni B, Geneix J, Finetti P, Zemmour C, et al: Frequency, prognostic impact, and subtype association of $8 \mathrm{p} 12,8 \mathrm{q} 24,11 \mathrm{q} 13,12 \mathrm{p} 13,17 \mathrm{q} 12$, and 20q13 amplifications in breast cancers. BMC cancer 2006, 6:245.

64. Creighton CJ, Kent Osborne C, van de Vijver MJ, Foekens JA, Klijn JG, Horlings HM, Nuyten D, Wang Y, Zhang Y, Chamness GC, et al: Molecular profiles of progesterone receptor loss in human breast tumors. Breast Cancer Res Treat 2009, 114(2):287-299.

65. Carracedo A, Salido M, Corominas JM, Rojo F, Ferreira BI, Suela J, Tusquets I, Corzo C, Segura M, Espinet B, et al: Are ER+PR+ and ER+PR- breast tumors genetically different? A CGH array study. Cancer Genet 2012, 205(4):138-146.

66. Ly M, Valent A, Diallo G, Penault-Lorca F, Dumke K, Marty V, Viehl P, Lazar V, Job B, Richon C, et al: Gene copy number variations in breast cancer of Sub-Saharan African women. Breast 2013, 22(3):295-300.

67. Ioannidis P, Mahaira L, Papadopoulou A, Teixeira MR, Heim S, Andersen JA Evangelou E, Dafni U, Pandis N, Trangas T: 8q24 Copy number gains and expression of the c-myc mRNA stabilizing protein CRD-BP in primary breast carcinomas. Int J Cancer 2003, 104(1):54-59.

68. Karlseder J, Zeillinger R, Schneeberger C, Czerwenka K, Speiser P, Kubista E, Birnbaum D, Gaudray P, Theillet C: Patterns of DNA amplification at band q13 of chromosome 11 in human breast cancer. Gene Chromosome Canc 1994, 9(1):42-48.

69. Hu G, Chong RA, Yang Q, Wei Y, Blanco MA, Li F, Reiss M, Au JL, Haffty BG, Kang Y: MTDH activation by $8 q 22$ genomic gain promotes chemoresistance and metastasis of poor-prognosis breast cancer. Cancer Cell 2009, 15(1):9-20.

70. Walker LC, McDonald M, Wells JE, Harris GC, Robinson BA, Morris CM: Dual-color fluorescence in situ hybridization reveals an association of chromosome $8 \mathrm{q} 22$ but not 8 p21 imbalance with high grade invasive breast carcinoma. PloS One 2013, 8(7):e70790.

71. Mesquita B, Lopes P, Rodrigues A, Pereira D, Afonso M, Leal C, Henrique R, Lind $G E$, Jeronimo $C$, Lothe RA, et al: Frequent copy number gains at 1q21 and $1 \mathrm{q} 32$ are associated with overexpression of the ETS transcription factors ETV3 and ELF3 in breast cancer irrespective of molecular subtypes. Breast Cancer Res Treat 2013, 138(1):37-45.

72. Curtis C, Shah SP, Chin SF, Turashvili G, Rueda OM, Dunning MJ, Speed D, Lynch AG, Samarajiwa S, Yuan Y, et al: The genomic and transcriptomic architecture of 2,000 breast tumours reveals novel subgroups. Nature 2012, 486(7403):346-352.

73. Shahbain H, Cooper C, Gerami P: Molecular diagnostics for ambiguous melanocytic tumors. Semin Cutan Med Surg 2012, 31(4):274-278.

74. Nijhawan RI, Votava HJ, Mariwalla K: Clinical application and limitations of the fluorescence in situ hybridization (FISH) assay in the diagnosis and management of melanocytic lesions: a report of 3 cases. Cutis 2012, 90(4):189-195.

75. Bastian BC, LeBoit PE, Hamm H, Brocker EB, Pinkel D: Chromosomal gains and losses in primary cutaneous melanomas detected by comparative genomic hybridization. Cancer Res 1998, 58(10):2170-2175.

76. Bastian BC, Olshen AB, LeBoit PE, Pinkel D: Classifying melanocytic tumors based on DNA copy number changes. Am J Patho/ 2003, 163(5):1765-1770.

77. Horst BA, Fang Y, Silvers DN, Busam KJ: Chromosomal aberrations by 4-color fluorescence in situ hybridization not detected in Spitz nevi of older individuals. Arch Dermatol 2012, 148(10):1152-1156.

78. Bangash HK, Romegialli A, Dadras SS: What's new in prognostication of melanoma in the dermatopathology laboratory? Clin Dermatol 2013, 31(3):317-323

79. Julia F, Thomas L, Dalle S: New therapeutical strategies in the treatment of metastatic disease. Dermatol Ther 2012, 25(5):452-457.

80. Pajor G, Alpar D, Kajtar B, Melegh B, Somogyi L, Kneif M, Bollmann D. Pajor L, Sule N: Automated signal pattern evaluation of a bladder cancer specific multiprobe-fish assay applying a user-trainable workstation. Microsc Res Tech 2012, 75(6):814-820.

81. Raimondo F, Gavrielides MA, Karayannopoulou G, Lyroudia K, Pitas I, Kostopoulos I: Automated evaluation of Her-2/neu status in breast tissue from fluorescent in situ hybridization images. IEEE Trans Image Process 2005, 14(9):1288-1299.

82. Theodosiou Z, Kasampalidis IN, Karayannopoulou G, Kostopoulos I, Bobos M, Bevilacqua G, Aretini P, Starita A, Lyroudia K, Pitas I: Evaluation of FISH image analysis system on assessing HER2 amplification in breast carcinoma cases. Breast 2008, 17(1):80-84.

83. Kilpatrick MW, Sheehan CE, Marganski WA, Tafas T, Ross MS, Ross JS: Determination of HER2 gene status by fully automated fluorescence microscopy. Anal Quant Cytol Histol 2011, 33(4):205-210. 
84. Kajtar B, Mehes G, Lorch T, Deak L, Kneifne M, Alpar D, Pajor L: Automated fluorescent in situ hybridization (FISH) analysis of $t(9 ; 22)(q 34 ; q 11)$ in interphase nuclei. Cytometry A 2006, 69(6):506-514.

85. Stumm M, Wegner RD, Bloechle M, Eckel H: Interphase M-FISH applications using commercial probes in prenatal and PGD diagnostics. Cytogenet Genome Res 2006, 114(3-4):296-301.

86. Chyhrai A, Sanjmyatav J, Gajda M, Reichelt O, Wunderlich H, Steiner T, Tanovic E, Junker K: Multi-colour FISH on preoperative renal tumour biopsies to confirm the diagnosis of uncertain renal masses. World J Urol 2010, 28(3):269-274.

87. Schramm M, Wrobel C, Born I, Kazimirek M, Pomjanski N, William M, Kappes R, Gerharz CD, Biesterfeld S, Bocking A: Equivocal cytology in lung cancer diagnosis: improvement of diagnostic accuracy using adjuvant multicolor FISH, DNA-image cytometry, and quantitative promoter hypermethylation analysis. Cancer Cytopathol 2011, 119(3):177-192.

88. Anderson K, Lutz C, van Delft FW, Bateman CM, Guo Y, Colman SM, Kempski H, Moorman AV, Titley I, Swansbury J, et al: Genetic variegation of clonal architecture and propagating cells in leukaemia. Nature 2011, 469(7330):356-361.

89. Janssens A, Van Roy N, Poppe B, Noens L, Philippe J, Speleman F, Offner F: High-risk clonal evolution in chronic B-lymphocytic leukemia: single-center interphase fluorescence in situ hybridization study and review of the literature. Eur J Haematol 2012, 89(1):72-80.

90. Wawrzyniak E, Kotkowska A, Blonski JZ, Siemieniuk-Rys M, Ziolkowska E, Giannopoulos K, Robak T, Korycka-Wolowiec A: Clonal evolution in CLL patients as detected by FISH versus chromosome banding analysis, and its clinical significance. Eur J Haematol 2013, 92(2):91-101.

91. Wang YC, Hu LP, Lin D, Li CW, Yuan T, Jia YJ, Tian Z, Tang KJ, Wang M, Wang JX: Detection of heterogeneity and evolution of subclones in $\mathrm{t}(8 ; 21)$ AML by QM-FISH. Zhonghua Xue Ye Xue Za Zhi 2013, 34(10):844-850.

92. Vital AL, Tabernero MD, Crespo I, Rebelo O, Tao H, Gomes F, Lopes MC, Orfao A: Intratumoral patterns of clonal evolution in gliomas. Neurogenetics 2010, 11(2):227-239.

93. Zhang S, Shao Y, Hou G, Bai J, Yuan W, Hu L, Cheng T, Zetterberg A, Zhang J: QM-FISH analysis of the genes involved in the G1/S checkpoint signaling pathway in triple-negative breast cancer. Tumour Biol 2013. (Epub ahead of print)

94. Tomao F, Papa A, Rossi L, Strudel M, Vici P, Lo Russo G, Tomao S: Emerging role of cancer stem cells in the biology and treatment of ovarian cancer: basic knowledge and therapeutic possibilities for an innovative approach. J Exp Clin Cancer Res 2013, 32:48.

95. Li Z: CD133: a stem cell biomarker and beyond. Exp Hematol Oncol 2013, 2(1):17.

96. Schwab CJ, Jones LR, Morrison H, Ryan SL, Yigittop H, Schouten JP, Harrison $\mathrm{CJ}$ : Evaluation of multiplex ligation-dependent probe amplification as a method for the detection of copy number abnormalities in B-cell precursor acute lymphoblastic leukemia. Gene Chromosome Canc 2010, 49(12):1104-1113.

97. Cheng T: Cell cycle inhibitors in normal and tumor stem cells. Oncogene 2004, 23(43):7256-7266.

doi:10.1186/2050-7771-2-3

Cite this article as: Hu et al.: Fluorescence in situ hybridization (FISH): an increasingly demanded tool for biomarker research and personalized medicine. Biomarker Research 2014 2:3.

\section{Submit your next manuscript to BioMed Central and take full advantage of:}

- Convenient online submission

- Thorough peer review

- No space constraints or color figure charges

- Immediate publication on acceptance

- Inclusion in PubMed, CAS, Scopus and Google Scholar

- Research which is freely available for redistribution

Submit your manuscript at www.biomedcentral.com/submit 